\title{
Silver Linings and Storm Clouds: Divergent Profiles of Student Momentary Engagement Emerge in Response to the Same Task
}

Associate Professor Jennifer E. Symonds

School of Education, University College Dublin, Ireland

jennifer.symonds@ucd.ie

Ph. +35317167995

Professor James B. Schreiber

School of Nursing, Duquesne University, USA

schreiberj@duq.edu

Assistant Professor Benjamin M. Torsney

College of Education, Temple University, USA

btorsney@temple.edu

\section{Keywords}

Momentary engagement, student engagement, classroom engagement, motivation; latent profile analysis

\section{Acknowledgements}

The research in this manuscript was funded by the Irish Research Council, through a Research for Policy and Society award made to Jennifer Symonds (Project ID RfPS/2016/46).

\section{Publication Version}

This document is a post-print version of Symonds, J. E., Schreiber, J. B. \& Torsney, B. M. (2020). Silver linings and storm clouds: Divergent profiles of momentary engagement emerge in response to the same task. Journal of Educational Psychology. This post-print version is archived in accordance with the publisher's self-archiving policy. 


\title{
Silver Linings and Storm Clouds: Divergent Profiles of Student Momentary Engagement Emerge in Response to the Same Task
}

\begin{abstract}
Previous research has demonstrated that student motivation and engagement can take different forms across a variety of tasks at school or college. However, no research has yet examined the forms of student momentary engagement that emerge in response to a single task. Adolescent students $(N=196)$ from two low-income secondary schools in Dublin, Ireland, were given the same English grammar task to complete in a ten-minute period. We used systematic observation and post-task self-report measures to collect data on momentary cognition, emotion, motivation, and behavior. Using Latent Profile Analysis, we discovered seven main forms of momentary (dis)engagement: fully engaged, attentive but amotivated, attentive but disinterested, attentive but disaffected, distracted but motivated, disengaged, and deeply disengaged. Gender, ethnicity, academic self-efficacy, peer support and classmate cognitive engagement were notable predictors of group membership. The results should be useful to educators wanting to understand why students in their classrooms have a variety of responses to the same task.
\end{abstract}

\section{Keywords}

Momentary engagement, student engagement, classroom engagement, motivation; latent profile analysis 


\section{Educational Impact and Implications Statement}

- When teachers give a class of school students the same academic task, this can provoke many different types of engagement and disaffection that are linked to students' individual characteristics and the motivation of other students in the class.

- Students who appear to be attentive while doing an academic task can simultaneously be demotivated and disaffected with the task.

- Peer support for learning and social inclusion, and individual self-efficacy, are important and malleable protective factors for momentary engagement in classwork.

- The design of academic tasks should ideally be calibrated for individual students in the classroom to promote momentary engagement. 


\section{Silver Linings and Storm Clouds: Four Profiles of Student Momentary Engagement Emerge in Response to the Same Task}

School students encounter many different academic tasks in a typical day at school. Arguably, teachers should aim to support students' engagement in those tasks, because engagement enables learning (Howard-Jones et al., 2018). However, supporting engagement in classrooms is a complex undertaking, given that researchers are finding many ways that momentary task engagement can vary across students who are doing the same task, even if the task is highly stimulating (e.g., Salmela-Aro et al., 2016). Within classrooms, ratings of student momentary task engagement made by students, teachers and observers, have varied across individual students (Kuo et al., 2018), demonstrating that individual students can be engaged at different levels compared to each other when doing the same task.

Furthermore, even if two students have the same overarching level of engagement, there may be interesting differences in how their engagement manifests, and these differences can have implications for learning. Following the perspective that momentary task engagement is a dynamic system created by the non-linear co-action of affective-motivational, cognitive, and behavioral components, that can be enacted with varying degrees of agency (Symonds et al., 2019), it might be possible that one student could experience higher levels of motivation and lower levels of on-task behavior, compared to another student with lower levels of motivation and higher levels of on-task behavior, but the two students' overall level of task engagement as the average or sum of these components would be the same.

This presents an interesting third possibility that there could be interindividual heterogeneity within individual momentary task engagement, meaning that within a classroom of students there could be common yet discrete forms of engagement emerging during the same 
task. To date, researchers have studied the internal dynamics of engagement and motivation occurring across situations (Dietrich et al., 2019; Schmidt et al., 2018), but not within a single situation as we are focusing on here. Their method has been to collect data on task engagement and motivation on multiple occasions across different learning situations (spanning days, weeks and months), then to pool these situations into the same dataset, and generate one set of profiles out of all the observations. This method creates profiles of aggregated situational engagement occurring across many different types of task and learning situation.

Using situational data collected twice during each science lesson over 10 days of high schooling in the US, Schmidt et al., (2018) identified six common aggregated situational engagement profiles, with the most common profiles being high on one engagement dimension and low on the others (demonstrating internally divergent engagement). Furthermore, in a study of situational changes in motivation in a German undergraduate psychology class, Dietrich et al., (2019) found four motivational profiles using data collected three times during each of ten lessons. Of the four profiles, three reflected internally consistent high, medium, and low situational motivation, and one profile was of simultaneously high situational motivation and cost of doing the task. A similar profile of high task values and cost was found in an Australian sample of adolescents (Watt et al., 2019), indicating the cross-cultural reliability of this condition.

Both of the situational studies (Dietrich et al., 2017; Schmidt et al., 2018) established that typical profiles of situational engagement can be found across academic tasks and learning contexts. However, they do not give us information on which forms of engagement emerge momentarily in response to a single task. To further the field, it is necessary to examine how a 
specific task promotes different forms of engagement for different sub-groups of students, so that teachers can better plan tasks to encourage engagement for all students.

Typically, teachers use a standardized educational curriculum to plan their lessons. This requires teachers to teach subject specific tasks (e.g., in English language and literacy, mathematics, science, history, and geography). Class sizes also impact the types of tasks that teachers can teach. For example, it might be less difficult for teachers to deliver standardized tasks to students in larger classrooms, compared to coordinating individualized project-based work. Resources for learning can also impact on pedagogy, with teachers working in higher income countries having more physical resources for learning, compared to those in lower income countries who might just have a blackboard and chalk. Accordingly, there is a wide variety of task conditions that students can experience in schools. This calls for more research on individual tasks to help educators plan their lessons to avoid tasks that create educational disaffection and to harness tasks that promote engagement.

Furthermore, students might have a variety of responses to the same task, even if the task is highly engaging. Currently there is no research on the extent to which student responses vary within the same task. This type of research is needed to ascertain which individual characteristics and personal and social experiences are important for engagement, and consequentially for learning in school contexts. Studies of individual learning tasks can open avenues of research on motivational resilience (Skinner, 2016), to explain why some students do better in school than others, even after controlling for cognitive ability.

The aims of this study were therefore to investigate interindividual heterogeneity within individual momentary task engagement occurring during a single, standardized task, and to test the extent to which individual characteristics (gender, social disadvantage, and age), subjective 
factors (perceived relationships with teachers, peers and parents, self-efficacy, and educational goals), and objective factors (classmates' average behavioral, emotional and cognitive engagement) might predict these engagement profiles. By ensuring that all students completed the same task, the predictors of engagement profiles are task specific, rather than being general predictors of engagement across a variety of tasks. In identifying profiles and predictors in the context of a single task, our study advances the field of research on profiles of situational engagement and motivation.

\section{Momentary Task Engagement}

Engagement is often researched as a multidimensional construct, comprising affectivemotivational, behavioral, and cognitive components (e.g., Christenson et al., 2012; Fredericks et al., 2004; Sinatra et al., 2015). It can also be conceptualized as a multilevel construct, with engagement in academic tasks nested in engagement in classrooms, engagement in classrooms nested in engagement in schools, and engagement in schools nested in engagement in pro-social institutions (Skinner \& Pitzer, 2012). This multilevel conceptualization draws attention to the importance of grain size (Sinatra et al., 2015) when researching student engagement, with grain size meaning "the level at which engagement is conceptualized, observed, and measured" (Sinatra et al., 2015, p. 2).

The concept of grain size can be applied to the methodological dimensions of time, agent, and task (Symonds et al., 2019). Momentary engagement occurs at the micro-level grain size of momentary time, at the micro-level grain size of a specific task, and at the micro-level grain size of individual student experiences. In comparison, the broader notion of school engagement (e.g. Wang et al., 2017) is often researched at the macro-level grain size of attitudes, effort, and participation occurring across a longer time period such as a school year or years, at the macro- 
level grain size of school as an institution, and at the macro-level grain size of a large groups of students such as all of those in a school or grade. Somewhere between momentary task engagement and school engagement is classroom engagement (Skinner \& Pitzer, 2012; Skinner, 2016), concerning students' investment and involvement in classroom activities (such as learning a specific subject).

Momentary task engagement can be understood using the same general framework of emotion, cognition, agency, and behavior that is often applied to classroom and school engagement. However, momentary engagement is proposed to operate as a rapid, non-linear dynamic system where motivation, emotion, and mental and physical action continually shape and are shaped by the emergent property of engagement as they co-act in context (Symonds et al., 2019). Within a dynamic system, parts can often operate unpredictably even if a great deal is known about them (Taleb, 2018). The momentary engagement system responds sensitively to the task context and setting; therefore, both must be considered when trying to understand patterns and predictors of momentary engagement. For example, a student's engagement in doing homework while the rest of their siblings watch TV in the adjoining room, might be quite different to their engagement in conducting a science experiment the next day in class with their friends. Accordingly, different forms of engagement can emerge in relation to different tasks, and different individual experiences of doing the task.

Following Skinner (2016), the opposite of momentary engagement is momentary disaffection, which includes motivational, affective, and behavioral indicators of a loss of energy, motivation, and persistence. During momentary disaffection, students can become inattentive and distractible, experience negative deactivating or activating academic emotions (including disinterest, boredom, frustration, and anger), and appraise the task as futile or overly 
challenging. In this perspective, disengagement is a behavioral indicator of disaffection, and refers to where students stop doing the task.

The momentary engagement research perspective can trace its roots to the concept of flow (Csikszentmihalyi, 2008), which refers to being in a state of complete absorption, i.e., “intense concentration and heightened interest" (Shernoff et al., 2016, p. 53), with a task or other type of activity (e.g., skiing). This concept has inspired researchers to study students' optimal learning moments at school (e.g., Schneider et al., 2016). However, not every task at school is likely to inspire optimal levels and types of engagement (Shernoff et al., 2016). This emphasizes that research should focus not only on tasks that are designed to be absorbing but also on other types of tasks that might be less engaging for students under typical circumstances. Accordingly, research on momentary engagement moves beyond flow, and considers situations and tasks that promote many prospective forms of engagement and disaffection.

\section{Facilitators of Momentary Task Engagement}

Skinner (2016) proposes two main types of facilitators of students' engagement in the classroom: perceived facilitators (what students think and feel about themselves and their experiences), and objective facilitators (students' actual classroom experiences).

The first set of facilitators are students' perceptions of their relationships with teachers, parents and classmates, their perceived competence and efficacy, their beliefs about the value of schooling, and their goal orientations. Perceived social support from peers can protect against declines in students' participation in school extracurricular activities, and valuing of school but at higher levels can increase the risk of non-compliance with education (Wang \& Eccles, 2012 a). Furthermore, perceived support from teachers and parents can protect against declines in emotional engagement with schooling (Wang \& Eccles, 2012). Self-efficacy is found to facilitate 
the time that students spend studying, i.e. an aspect of their behavioral engagement (Xie et al., 2019), and changes in students' educational aspirations across high school have reciprocal relations with the development of students' engagement (Wang \& Eccles, 2012 b).

The second set of facilitators are students' actual social interactions, classroom organizational systems, curriculum, and pedagogy. These facilitators are generally studied using observational methods. Observations of teachers' emotional support and the quality of classroom organization have positively predicted students' observed behavioral engagement and selfreported emotional and cognitive engagement, (Rimm-Kaufman et al., 2015). Having a greater dispersal of friendships across students within a classroom (social network equity) has also been found to predict individual students' behavioral engagement (Cappella et al., 2013).

Regarding classroom organization, the number of students in a class influences engagement, with larger class size associating with decreases in observed time on task for individual students (Blatchford et al., 2011). Finally, regarding curriculum and pedagogy, students in science classrooms were more likely to belong to groups of highly engaged or highly disengaged students if doing lab work (i.e., lab work incurred extreme responses), were more disengaged during individual work, were less reluctant to engage during lectures, and had more positive forms of engagement when they were given more choice over their learning (Schmidt et al., 2018).

Individual characteristics can also influence momentary task engagement, given their well-documented role in shaping many types of learning experiences and outcomes. These include an individual's gender, ethnicity, family economic situation, and age. Being female has positively predicted students' self-reported attention and participation in class, amount of homework completed for class (Lau \& Roeser, 2002), observer and teacher rated behavioral 
engagement, and student rated cognitive engagement (Rimm-Kaufman et al., 2015). Being female has also predicted having more compliant forms of engagement (Watt et al., 2017) and being in a more engaged group of students (Virtanen et al., 2018). Being male has positively associated with students' situational interest and participation (Patall et al., 2016), and being in a less engaged group of students (van Rooij et al., 2017 \& Virtanen et al., 2018). The findings across these studies suggest that maleness associates with higher and lower forms of engagement, depending on which type of engagement is being measured, and that being female generally has positive associations with behavioral engagement.

In terms of race, being Black, Hispanic, or other ethnic minority, versus being Caucasian or Asian, has positively predicted students working hard across tasks in an ESM study (Patall et al., 2016). In person-oriented research, African American students were more likely to have high but decreasing behavioral engagement compared to high stable behavioral engagement, whereas Latino students were more likely to have higher stable emotional engagement compared to decreasing emotional engagement across high school (Li \& Lerner, 2011). Other studies have found no differences in levels, or types of engagement by ethnicity (Lau \& Roeser, 2002; Wang \& Peck, 2013). This indicates that associations between ethnicity and engagement may be highly context dependent.

Regarding social disadvantage, having a free or reduced-price lunch has positively predicted emotional situational engagement (i.e., fun, interest, and enjoyment in math class today) measured at three occasions during the school year (Rimm-Kaufman et al., 2015). Having lower socioeconomic status has also associated with belonging to groups of students with more negative forms of behavioral and emotional engagement (Li \& Lerner, 2011). Furthermore, in an ESM study of classroom engagement, social disadvantage had no impact on behavioral and 
cognitive engagement (Patall et al., 2016). Accordingly, the findings on social disadvantage and engagement are mixed and more research is needed to clarify the divergence in associations.

Finally, in person-oriented research, younger students were more likely to belong to a highly engaged group of students (Watt et al., 2017), fitting with longitudinal research on declines in students' enjoyment and interest in studying (e.g. Symonds \& Galton, 2014). However, in variable centered research, age had no association with situational engagement (Rimm-Kaufman et al., 2015). These contradictory findings call for more research on age and engagement.

\section{Person-Oriented Analyses of Momentary Task Engagement}

The current research aims to extend the literature by examining whether different forms of engagement emerge in response to a single task. An ideal approach for studying different engagement forms is person-oriented analysis where researchers seek to uncover hidden profiles or classes from the data or cluster based on the probability of belonging to a certain group and some deductive specification (Schreiber, 2017).

To identify prior research that described person-oriented analyses of momentary task engagement, we carried out a systematic literature search (which underpins but is not equivalent to a systematic literature review) using the Pro-Quest databases Australian Education Index, ERIC, PsychInfo, and Social Sciences Premium Collection (Education, Social Science). The search was conducted on August $8^{\text {th }}, 2019$. The abstracts of peer reviewed journal articles published in English during the past 10-years were searched using the terms (engagement AND school AND (profile OR cluster OR mixture model*) NOT randomized trial). A total of 354 abstracts were returned, including duplicates. These were screened using the inclusion criteria that they must contain a person-oriented analysis of student engagement created using variables 
representing at least two of the three common engagement dimensions (behavior, cognition, and emotion/motivation) in typically developing samples of school students. Common reasons for excluding abstracts were that engagement was a predictor or outcome of the person-oriented analysis, the word profile did not refer to a person-oriented analysis, the word cluster referred to a randomized controlled trial, the student population was special needs, and the abstract mentioned engagement but the analysis only included motivational variables (e.g. task-value). Where an abstract did not give enough detail, the study was retained for full text screening. This resulted in 29 studies remaining for full text screening.

After the methods sections of the 29 studies were assessed, 12 studies remained that fit our inclusion criteria. We then classified these according to the grain size of engagement used in each person-oriented analysis. This revealed that 10 studies focused on the broader grain size of school engagement, using data collected either cross-sectionally or up to three times in longitudinal waves. Only two studies were focused on the smaller grain size of situational or momentary task engagement. The search results are displayed in Figure 1 as a flow diagram and in Table 1 listing the 12 person-oriented analyses of school or momentary engagement.

Of the school engagement studies $(n=10)$, two studies generated profiles containing engagement indicators and constructs external to engagement (including achievement variables, self-concept, parent academic involvement, and substance use) (Maynard et al., 2012; Widlund et al., 2018). The remaining eight studies generated profiles of engagement containing cognitive, affective and behavioral indicators of engagement. These eight studies fit with our focus on explaining emergent forms of engagement and their predictors, and we briefly review these studies below, according to how they conceptualized and measured engagement. 
In the first category, four studies measured school engagement as energy, dedication and absorption (Salmela-Aro \& Upadyaya, 2012), and combined this with a measure of school burnout (Salmela-Aro et al., 2009) to create profiles of engagement and burnout. One study was a cross-national comparison of Finnish and US data (Salmela-Aro, et al., 2016 a) and the other three focused on Finnish youth (Salmela-Aro et al., 2016 b; Tuominen-Soini \& Salmela-Aro, 2014; and Virtanen et al., 2018). Across the studies, between four and five classes of engagement were evaluated as a best fit to the data. In all studies, there was a highly engaged class with low levels of burnout, and a burned-out class with lower levels of engagement. The more engaged classes were predicted by higher situational resources (Salmela-Aro et al., 2016), being male (Tuominen-Soini \& Salmela-Aro, 2014), being female (Virtanen et al., 2018), and having higher teacher and family support, higher self-esteem and higher educational aspirations (Virtanen et al., 2018). The most disengaged classes were predicted by higher situational demands (SalmelaAro et al., 2016), greater truancy, and being male (Virtanen et al., 2018).

In the second category, three studies measured school engagement using indicators of emotional, cognitive and behavioral engagement. The measures for each indicator varied across studies. Using mixture latent growth curve modelling, Li and Lerner (2011) generated four longitudinal profiles of behavioral engagement, and four longitudinal profiles of emotional engagement. The higher, relatively stable behavioral and emotional engagement profiles were predicted by students having higher SES and being female. Within ethnic groups, African American adolescents were more likely to be in the transitory decreasing and moderate behavioral engagement profiles, than in the high engagement profile for behavioral engagement, and Latino youth were more likely to be in the highest profile compared to the high decreasing profile for emotional engagement. 
In cross-sectional research, Wang and Peck (2013) computed five profiles of emotional, cognitive and behavioral engagement at Grade 9, and used these to predict student outcomes at Grades 10 and one year after expected high school graduation. The profiles were highly engaged (17\%), moderately engaged (46\%), minimally engaged (14\%), emotionally disengaged - with low emotional engagement but moderate cognitive and behavioral engagement (10\%), and cognitively disengaged - with low cognitive engagement but moderate emotional and behavioral engagement (13\%). There were no gender, SES nor ethnic differences between the profiles. Watt et al. (2017) also used complex mixture modelling to identify different profiles of cognitive, behavioral and emotional engagement in math classrooms. The three resultant profiles were engaged (55\%), compliant - with higher behavioral engagement and lower cognitive and emotional engagement (37\%) and disengaged (7\%). The engaged profile was predicted by younger age, and higher grades. The disengaged and engaged profiles were predicted by being male, and the compliant profile was predicted by being female. Similar to the Finnish studies described above, in all the studies of behavioral, cognitive and emotional engagement profiles, a highly engaged and a disengaged profile emerged. The additional profiles were either higher or lower in engagement across indictors, or had one engagement indicator (e.g., behavior) higher than the others (e.g. lower cognition and emotion; Watt et al., 2017).

Turning to the two person-oriented analyses of momentary task engagement, one (Schmidt et al., 2018) used the perspective of engagement as a multidimensional construct (as presented by Fredericks et al., 2004), whilst the other drew on flow theory and game-based learning (Hsieh, Lin, \& Hou, 2016). In the latter study, researchers clustered three variables: students' video game behavior representing accuracy, scope and correctness, students' flow antecedents of challenge, control, and goals, and students' flow experiences of concentration, 
time distortion, and enjoyment. Three main profiles emerged: low on all indicators (21\%), low flow antecedents and high flow (35\%), and high flow antecedents, moderate behavior, and moderate flow (44\%). This study reveals that students can have high flow experiences while video gaming, even if they report poor conditions for Flow (e.g., low challenge, control, and a lack of goals).

Schmidt et al. (2018) used ESM to study high school students' emotional, cognitive, and behavioral engagement in science lessons, twice during each lesson for ten days in total. Using Ward's clustering method, they identified six clusters: low engagement (22\% of data points), low emotion and cognition and moderate behavior (18\%), moderate emotion and cognition and low behavior (19\%), low emotion, moderate cognition and high behavior (13\%), moderate engagement (18\%) and high engagement (10\%). All variables were constructed using self-report. Arguably, the emotional and cognitive items could represent different aspects of affectivemotivational engagement. The emotional engagement items referred to interest and enjoyment, while the cognitive engagement items referred to the importance of doing schoolwork for self and future self (i.e. how important was what you were doing to you?), which have emerged in qualitative measure development research as indicators of emotional engagement (Fredricks et al., 2016). As discussed earlier, the momentary engagement profiles were predicted by students' choice in learning and by the type of activity students were doing in science classrooms.

Regardless of variables used and item selection, the latent profile studies of momentary engagement provide an excellent demonstration that large profiles exist that have divergent internal dynamics (e.g. higher on some indicators and lower on others), indicating that divergent dynamics might be normative depending on the task. 


\section{The Current Study}

The current study explores the possibility of interindividual heterogeneity within individual momentary task engagement. This study will help to build the evidence-base on how and why students might have different psychological reactions when faced with the same task. Furthermore, this study extends the research on person-oriented analyses of task-engagement, by researching at a narrower grain size of timing (engagement in a single task) compared to Schmidt et al.'s (2018) ESM study of momentary engagement in multiple tasks. This allows the findings to be interpreted in relation to the exact task conditions described later in our methods section. Because research on different forms of momentary task-engagement is in its infancy, our research questions are exploratory.

1. What are the typical forms of engagement occurring within students across classrooms? Here we assume that profiles of consistently higher and lower engagement will emerge, following the results of prior latent profile analyses of school engagement and momentary task engagement (e.g., Salmela-Aro et al., 2016; Schmidt et al., 2018; \& Watt et al., 2017). We also assume that profiles of internally divergent forms of momentary task engagement will emerge, following latent profile analyses of momentary task engagement (Hsieh et al., 2016; Schmidt et al., 2018), and school engagement (Wang \& Peck, 2013 \& Watt et al., 2017).

2. Which individual characteristics best predict these typical forms of engagement? Following other latent profile analyses of school engagement, we were interested in the predictive utility of gender (Li \& Lerner, 2011; Tuominen-Soini \& Salmela-Aro, 2014; Watt et al., 2017 \& Virtanen et al., 2018), ethnicity (Li \& Lerner, 2011), and social disadvantage (Li \& Lerner, 2011). 
3. Which perceived and objective facilitators of engagement best predict these typical forms of engagement? Skinner (2016) outlined key perceived facilitators of classroom engagement that include relationships with teachers, peers and family, personal efficacy and competence, valuing education and educational goals. Here, we assumed that more positive forms of engagement will associate with higher perceived quality of relationships with teachers, peers and family (Wang \& Eccles, 2012 a), higher selfefficacy (Xie et al., 2019), and greater value attributed to education (Wang \& Eccles, 2012 b). Skinner (2016) also outlines objective facilitators of classroom engagement, including the social interactions between students and teachers and peers, curriculum and pedagogy. In this study we were interested to discover the impact of classmates' momentary engagement, on individual students' momentary engagement, following Cappella et al. (2013) who found no association between classmate behavior and individual student engagement, but a positive association between classmate relational climate and individual student engagement.

\section{Materials and Methods}

\section{Participants and Procedures}

Students $(N=325$; age in years: $M=13.07, S D=1.11)$, from two secondary schools with a classification of social disadvantage located in in Dublin, Ireland, were recruited into the study through school and parental consent, and personal assent. Students were in their first and second year of secondary schooling in School A, and in their first, second and third year of secondary schooling in School B. The students completed a self-report questionnaire collecting data on their dispositions regarding self and school (e.g. teacher, peer and family relationships, and academic self-efficacy), at three time points across the school year. 
During the middle time point, all students in their first and second year of secondary schooling $(\mathrm{N}=278)$ were targeted for the momentary assessment. Of those students, 196 were present on the day of the momentary assessment and 86 were absent. We checked for systematic differences in missingness using the variables of male vs. female, age in months, Irish vs. other ethnicity, and perceived family economic advantage (measured at the first and last time point). This yielded an insignificant result on Little's Missing Completely at Random (MCAR) test, suggesting that the cases were missing completely at random. We also analyzed missingness using multiple linear regression, using the same predictors of missingness and the missing variable $(1=$ present, $0=$ missing $)$ as the dependent variable. There were no significant results.

The momentary assessment involved a ten-minute long standardized literacy task administered in the students' ordinary lessons. The task was administered by one researcher, while a second researcher video recorded the class. This procedure occurred for each of 16 classes across the two schools. Students were prompted to approach the task in the same way they would normally approach tasks in their English lesson. Immediately after the task, students completed a momentary engagement assessment. Trained researchers coded the video recordings using a systematic observation schedule.

The measures of momentary engagement, subjective and objective facilitators of engagement, were administered during the momentary assessment lesson. The measures of individual characteristics were collected during the first time point (gender, age, and ethnicity) and the last time point (economic advantage). 


\section{Measures}

\section{Momentary Task Engagement}

Momentary task engagement was measured using three dimensions: emotional (affective-

motivational), cognitive, and behavioral. The first two dimensions were measured using Shernoff et al.'s (2016) Record of Experience (RoE) measure, which was developed for use in experience sampling of engagement in high school students. The RoE comprises 17 items measuring different aspects of momentary learning experience, many of which can be usefully repurposed for measuring the psychological dimensions of momentary engagement including emotion and cognition. The items are scored using a 5-point Likert type scale ( $1=$ not at all; $5=$ very $)$.

\section{Momentary Emotional Engagement}

We used three items $(\alpha=.81)$ from the RoE to represent students' momentary affectivemotivational state immediately following the task: How important was this activity or topic to you?, Was it interesting?, and Did you enjoy what you were doing?.

\section{Momentary Cognitive Engagement}

We used an additional three items $(\alpha=.69)$ from the RoE (Shernoff et al., 2016) to represent momentary cognitive processes during the task: How hard were you concentrating?, Were you using a high level of skill?, and How hard were you trying?

\section{Momentary Behavioral Engagement}

The Observational Research and Classroom Learning Evaluation (ORACLE) Pupil Record systematic observation schedule (Hargreaves \& Galton, 2002) measured students' on and off-task behavior. Videos of each class $(N=16)$ were watched by trained research assistants, who observed each student individually across the 10-minute task period. The research assistants coded student's behavior every 30 seconds (20 intervals in total), into a 12-category observation 
schedule. Inter-rater coder reliability was checked by comparing agreement across $20 \%$ of case between the first author's codes and the group of trained research assistants coding independently of each other at the first (83\% agreement), tenth (81\% agreement), and nineteenth (75\% agreement) 30-second intervals. The on-task behavior composite variable consisted of the sum of the following on-task behaviors: (a) cooperating fully on task alone; (b) cooperating fully on task with a friend; (c) waiting for teacher, (d) paying attention to the teacher) was used to represent behavioral momentary task engagement. This created a scale ranging from $1-20$.

\section{Individual Characteristics}

Age

Students reported their year and month of birth. A continuous measure of months old was computed for the month of data collection.

\section{Male}

Students reported whether they identified as male, female, or other. Two students identifying as other had their gender data replaced with a missing value, to facilitate a binary comparison between males (1) and females (0).

\section{Family Economic Advantage}

Students were asked: In the past three months, how much of a problem did your family have because your parents could not buy the things your family needs and wants? This item was adapted from Mistry, Benner, Tan, and Kim (2009) and was measured on a 5-point Likert scale $(1=$ a very big problem; $5=$ no problem at all $)$.

\section{Ethnicity}

Categories of ethnic background were developed for the study, using prevalent and important ethnic groups in Ireland: Irish (71.8\%), Polish (3.7\%), any other European country 
(6.9\%), the Irish indigenous ethnic group Travellers (1.1\%); and United Nations world regions: African (2.1\%), Middle Eastern (0.5\%), Southeast Asian (2.1\%), East Asian (0.5\%); and mixed $(10.6 \%)$. Owing to the small sizes of non-Irish ethnic groups in the sample, we used a single variable of Irish (72\%) vs. any other ethnicity (28\%) in the analysis.

Subjective Facilitators of Momentary Task Engagement

All subjective facilitators were measured on a 6-point Likert scale $(1=$ never, $6=$ always).

\section{Academic Self-Efficacy}

Immediately following the task, students rated their academic self-efficacy on three items $(\alpha=.69)$ : I expect to do well in my lessons, I feel that I can learn most things in my lessons, and I feel confident in my ability as a student. The items were adapted from the Motivated Strategies for Learning Questionnaire (Pintrich et al.,1993).

\section{Educational Goals}

To capture the value of education to the students, we measured students' educational goals using three items adapted from the Student Engagement Instrument (Appleton et al., 2006) for use in Ireland: I hope to continue my education following secondary school, I think that continuing with education after secondary school is important, and I think that school is important for achieving my future life goals $(\alpha=.87)$.

\section{Teacher Support}

Three items measuring teacher support were taken from the Student Engagement Instrument (Appleton et al., 2006): Adults (e.g., teachers, school staff, principals) at my school listen to the students, My teachers are there for me when I need them, and At my school, teachers care about students $(\alpha=.87)$. 


\section{Peer Support}

Three Student Engagement Instrument (Appleton et al., 2006) items were used to measure peer support: Other students at my school are there for me when I need them, Other students at my school like me the way I am, and Other students at my school care about me $(\alpha=$ $.81)$.

\section{Family Support}

A further three items from the Student Engagement Instrument (Appleton, Christenson, Kim, \& Reschly, 2006) captured students' family support: When I have problems at school my family/guardian(s) are willing to help me, My family/guardian(s) want me to keep trying when things are tough at school, and When something good happens at school, my family/guardian(s) want to know about it $(\alpha=.70)$.

\section{Objective Facilitators of Momentary Task Engagement}

A method like group mean centering by classroom was used to create objective indicators of the extent to which each student's classmates were behaviorally, cognitively, and emotional momentarily engaged in the task. However, unlike group mean centering which gives the score of the individual relative to the mean of their group (e.g., how high or low an individual student is in comparison to the rest of their classmates) (Kelley et al., 2017), we calculated the average momentary task engagement of each students' group of classmates, to indicate the overall social context each student was embedded in. This increased the objectivity of the measure as a social predictor, as each student's score was subtracted from their classmates' scores as described in the method below.

1. Scores were created for each student, for each indicator of momentary task engagement $(\mathrm{a}=$ sum of behavioral engagement scores, $\mathrm{b}=$ average of emotional 
momentary task engagement items, $\mathrm{c}=$ average of cognitive momentary task engagement items).

2. The numbers of students with data on each indicator were computed for each classroom.

3. The scores were summed for each indicator, for each classroom (e.g. in a classroom of 17 students, all students' total scores for behavioral engagement were added together, making a classroom sum score of 250).

4. Each student's score was subtracted from their classroom sum score, for each indicator (e.g., subtracting the student's behavioral engagement score of 10 from the classroom sum score of 250).

5. The remaining score (e.g. 240) was divided by the total number of students in the classroom minus one, for each student (e.g. for Johanne Barnes, her classroom sum score minus her individual score was divided by the number of classmates she had that day, to represent the average level of that indicator for her classmates).

\section{The Task}

A standardized literacy task was constructed using material from an English grammar textbook. The task was in four sections: (a) prepositions (e.g., why are you talking whisper?), (b) punctuation (e.g., wheres the car asked the mechanic), (c) confusibles (e.g., the moon shone (pale, pail) across the sleeping town), and (d) clauses (e.g., Mary is digging in her garden. Mary is digging in her garden and whistling a tune). Students were asked to fill in the correct preposition, to punctuate the sentences, select the correct confusable, and write sentences of one to four clauses. There were no images in the task, and it was presented on double sided A4 (8.5" x 11") pages. The task written instructions were to complete as much of the task as the 
student could in 10 minutes, to work alone or with a friend (their choice), and to approach the task the same way they would normally approach tasks in their English class. Researchers read the instructions to the students and added that the students should not try to work harder than normal just because the researchers were in the room. After the task, students were asked to complete the post-task Record of Experience questions.

\section{Analysis}

\section{Latent Profile Analysis}

To answer the first research question of (What are the typical forms of engagement occurring within students across classrooms?), we conducted a latent profile analysis in Mplus version 8.3 using the three momentary task engagement variables measured at the individual level. The behavioral engagement scale was transformed by dividing the scores by four, to create a scale range $(0-5)$ similar to the emotional and cognitive engagement variables scale ranges $(1$ -5). This retained the original distribution of the behavioral engagement scale whilst improving the interpretability of the profile solutions.

The three variables were entered into Mplus. No covariates or cluster variables were added to the model, to allow the classes to form completely inductively based on the engagement indicators alone. We generated eight profile solutions. Model fit statistics of Akaike information criterion (AIC), sample size adjusted Bayesian information criterion (BIC), entropy, and the Bootstrapped likelihood ratio test (BLRT) were compared between solutions to inform the final selection (Nylund et al., 2007). Each model fit statistic provides guidance but does not determine any fixed cut off point; rather, they are exploratory, leaving the final selection of profile solution open to the researchers' judgements on ease of interpretation and theoretical importance (Oberski, 2016). Our handling of this process is described in the results section. 


\section{Multinomial Logistic Regression}

We addressed the second and third research questions (Which individual characteristics best predict these typical forms of engagement?, and Which perceived and objective facilitators of engagement best predict these typical forms of engagement?) using multinomial logistic regression in Mplus version 8.3. Three sets of variables were inputted simultaneously into the model: individual characteristics (male gender, age, Irish ethnicity, and family economic advantage); subjective variables (academic self-efficacy, educational goals, and teacher, peer and family support); and objective variables (classmate behavioral, emotional and cognitive engagement). This allowed us to examine the impact of individual characteristics on the profile membership, whilst simultaneously using these as control variables to better identify the unique contribution of the objective and subjective predictors. Comparison of unstandardized beta weights and odds ratios determined which variables best predicted membership of the different engagement profiles.

\section{Results}

Descriptive statistics for all study variables are displayed in Table 1. Following recommendations from the American Statistical Association (ASA) (Wasserstein, Schirm \& Lazar, 2019), $p$ values are used descriptively in the tables and our results are interpreted primarily based on the test statistic (e.g., unstandardized Beta weight) rather than on a probability statistic which has little utility with non-representative samples.

\section{Results for Research Question 1}

What are the Typical Forms of Engagement Occurring Within Students Across Classrooms? We ran the latent profile analysis for twelve successive solutions and evaluated these using a comparison of model fit statistics, and theoretical and practical utility judgements. 
Across the twelve solutions, the AIC decreased linearly, the BIC decreased linearly with a temporary hiatus across the eight and nine profile solutions, and the entropy increased linearly until a hiatus across the ten, eleven and twelve profile solutions (Table 4). Taken together, these statistics indicated that larger solutions $(\mathrm{k})$ were a better or equivalent fit compared to smaller solutions $(\mathrm{k}-1)$.

We also referred to the BLRT which evaluates the goodness of fit for k solution versus $\mathrm{k}$ -1 solution, based on the log likelihood difference calculated in a bootstrapped sample. This produces a robust measure of fit (Nylund et al., 2007). In our models, the BLRT indicated that the four profile solution fit better than the three profile solution, and that the seven profile solution fit better than the six profile solution.

Next, we checked the four and seven profile solutions to assess their theoretical utility (the patterns indicated for each profile) and practical utility (whether each profile was at least $1 \%$ of the sample size; $\mathrm{Ng}$ et al., 2019). Each profile (Table 4) was more than $1 \%$ of the sample size in both solutions. However, each distinct pattern of momentary engagement indicators observed in the four profile solution emerged in the seven profile solution, with the additional three profiles in the seven profile solution being more specific variants of these patterns. For example, the disengaged on all indicators profile observed in the four profile solution $(n=34)$ split into two classes in the seven profile solution of low $(n=26)$ and extremely low $(n=12)$ engagement. This gave the seven profile solution the advantage of three further theoretically distinct classes, enabling greater specificity in analysis.

Referring to the BLRT result, the AIC, BIC and entropy statistics, and these theoretical and practical considerations, we therefore selected the seven profile solution, based on the logic that (1) in these data, larger solutions were a better fit (indicated by the decreasing AIC and BIC, 
and by the increasing entropy), (2), that successive profile solutions did not make a significant difference to the model after the seven profile solution (indicated by the BLRT), and that (3) the seven profile solution retained the theoretical value of the four profile solution while having greater statistical clarity.

After selecting the seven profile solution, we ran descriptive statistics using the three momentary engagement variables, to help us identify quantitative and qualitative differences between the profiles (Table 5). A total of 196 cases were classified into the seven profiles. Below, we report on the most engaged to the least engaged profiles. The engaged profile ( $\mathrm{n}=54$, 28\%) had high levels of behavioral, emotional, and cognitive momentary engagement. Then, three more profiles with high levels of behavioral engagement emerged, however the attentive amotivated $(\mathrm{n}=18,9 \%)$ profile also had low lower levels of emotional engagement, the attentive disinterested $(n=62,32 \%)$ profile had moderate levels of emotional and cognitive engagement, and the attentive disaffected $(\mathrm{n}=12,6 \%)$ profile had low emotional and cognitive engagement. Finally, there were three profiles with lower levels of behavioral engagement. The distracted motivated $(\mathrm{n}=12,6 \%)$ profile was off-task but with higher emotional and cognitive engagement, the disengaged $(n=26,13 \%)$ profile had moderate to low scores on all indicators of momentary engagement, and the deeply disengaged $(\mathrm{n}=12,6 \%)$ profile had very low behavioral engagement, and low emotional and motivational engagement. Table 5 and Figure 2 display the mean scores for each profile.

\section{Results for Research Question 2}

Which individual characteristics best predict these typical forms of engagement? The multinomial logistic regression was run on using the four largest profiles, to enable meaningful statistical analysis of group differences. These profiles were: engaged $(n=54)$, attentive 
amotivated $(n=18)$, attentive disinterested $(n=62)$, and disengaged $(n=26)$ with the engaged profile as the reference category. Statistics for the regression are displayed in Table 6.

There were no age nor perceived economic differences between students in the engaged profile and the other three profiles. However, there were differences by gender and being ethnicity. Being female predicted being in the attentive disinterested profile $(\beta=-2.79, \mathrm{OR}=.06$, $p=<.001)$ and the attentive disaffected profile $(\beta=-.90, \mathrm{OR}=.41, p=<.001)$ but not the disengaged profile. Being Irish predicted being in the attentive disaffected profile $(\beta=-1.05$, OR $=.35, p=<.001)$ and the disengaged profile $(\beta=-1.30, \mathrm{OR}=.27, p=<.01)$.

\section{Results for Research Question 3}

Which subjective and objective facilitators best predict these typical forms of engagement? After controlling for individual characteristic differences in profile membership through their inclusion as predictors in the model, self-efficacy and peer support emerged as important predictors of profile membership across the subjective variables. Compared to the engaged profile, self-efficacy was lower in the disengaged profile $(\beta=-1.22$, OR $=.30, p=<$ $.001)$, the attentive disaffected profile $(\beta=-.54, \mathrm{OR}=.58, p=<.05)$ and the attentive disinterested profile $(\beta=-.89$, OR $=.41, p=<.01)$. Peer support was also lower in the attentive disinterested profile $(\beta=-1.02, \mathrm{OR}=.36, p=<.001)$ and the attentive disaffected profile $(\beta=-$ $.37, \mathrm{OR}=.69, p=<.05)$, and teacher support was lower in the disengaged profile $(\beta=-.64, \mathrm{OR}$ $=.53, p=<.05)$. Educational goals and family support were equivalently high across the four profiles tested.

Of the objective facilitators, only classmate cognitive engagement predicted profile membership. There, classmate cognitive engagement was lower in the attentive disinterested profile $(\beta=-2.96, \mathrm{OR}=.05, p=<.001)$ and attentive disengaged profile $(\beta=-1.51, \mathrm{OR}=.22, p$ 
$=<.01)$ compared to the engaged profile. Classmate behavioral and emotional engagement did not impact profile membership in this analysis.

Finally, we examined how the profiles were distributed across classrooms, using a simple cross-tabulation (Table 7). Visual examination of the statistics indicated that nearly all classrooms had at least some instances of every profile. This helps in interpreting the results of the multinomial logistic regression, as we should imagine for example that students in each profile would have been sitting in classes alongside students in the other profiles, at the time of the task.

\section{Discussion}

Understanding how students are likely to respond to specific types of tasks (e.g., an English or math task, or an exploratory versus close-ended task) is important for teachers so they can better plan how to effectively teach students with different engagement profiles. This study used quantitative methods to examine the range of engagement responses that students had to a single, standardized literacy task, and to assess which individual personal and social factors predicted those forms of engagement. First, using a latent profile analysis we uncovered seven main types of engagement responses: engaged (28\%), attentive amotivated (9\%), attentive disinterested (32\%), attentive disaffected (6\%), distracted motivated (6\%), disengaged (13\%), and deeply disengaged (6\%). Second, we ran a multinomial logistic regression to identify the strongest predictors of profile membership from three groups of variables: individual differences,

subjective facilitators of engagement, and objective facilitators of engagement. Below we discuss the findings for each research question, then conclude with general messages arising from the research to inform research and teaching. 


\section{Discussion of Research Question 1 Findings}

The seven momentary task engagement profiles that emerged in this study had similarities to profile analyses of school engagement found in other studies (e.g., Watt et al., 2017) and the only other profile analysis of momentary task engagement to date (Schmidt, 2018). Like in those other studies, two main profiles that emerged consisted of students who had either consistently high (engaged, 28\%) or low (disengaged, 13\%) scores on all indicators. Also, like the task engagement profile analysis presented by Schmidt et al. (2018), students in several of the other profiles had contradictory scores on the indicators (e.g., higher on one, and lower on the other). This suggests that across the profiles and the sample, the variables comprising momentary engagement did not have a consistent linear relationship. This fits with the perspective of dynamic systems, where although there are co-actions (relations) between parts, the nature or 'direction' of these relations differs depending on the individual student and context.

Although it could be speculated that these patterns are a methodological artefact, the evidence suggests not. The person-oriented methods used in our study and in Schmidt et al., (2018) were different, with Schmidt et al. (2018) using Ward's clustering method to classify cases from across multiple time points which is another robust form of person-oriented analysis. Clearly, the consistent pattern of results across both studies suggests that interindividual heterogeneity in individual scores is to be expected.

A key finding of this and prior studies is that across both multiple moments and tasks in science classrooms (Schmidt et al, 2018), and during a single literacy task, students had very different responses to each other, with many being behaviorally engaged but emotionally and cognitively disengaged, others being emotionally and cognitively engaged but behaviorally disengaged, and some having higher engagement, and some lower engagement. In our study, a 
simple cross-tabulation of profiles by classrooms demonstrated that the full set of profiles was apparent in most classrooms. In accordance with the dynamic systems perspective, experimenting with different tasks could change the prevalence of certain profiles altered (e.g., fewer attentive but disaffected, and more disengaged) in response to different task material. This would begin to build the knowledge base for educators on which types of tasks promoted more positive momentary engagement, extending what has already been learned about optimal learning moments across numerous tasks and situations (e.g. Schneider et al., 2016).

Considering each of the seven profiles within a dynamic systems perspective, the constant interaction between the more and less engaged groups have certain ramification. These interactions show, that if the less engaged profile has more control over the class, the fragility of the classroom dynamic system becomes higher (Taleb, 2018). According to Taleb, fragility refers to a "sensitivity to disorder" (p. 141), and if a classroom is more sensitive to disorder where there is asymmetric response to the disorder (e.g., the less engaged students are occupying more the teacher attention) - then the whole system will collapse. This is bit overstated; however, teachers, researchers, and students understand that classrooms that are sensitive to disorder tend to function poorly. For this reason, teaching students resilience strategies, having teachers that are overly prepared for the classroom, and having curricula that supports each individual student's learning is essential. In essence, understanding what a dynamic system looks like in a classroom and the student profiles that interact within that dynamic system is critical to supporting the wellbeing of that class.

\section{Discussion of Research Question 2 Findings}

This study made progress in identifying how selected individual characteristics predicted different forms of engagement, in the context of a single literacy task. There were no notable 
impacts of economic advantage or age on profile membership, however we did find significant results for gender and ethnicity.

Regarding gender, students were more likely to be attentive and disaffected or amotivated if they were female. This finding fits with prior research on two counts. First, female students are found to be less disruptive in class and have greater attention in the classroom (Archambault \& Dupéré, 2017). Also, in adolescence, female students are more likely to report negative selfperceptions for example lower self-worth, than male students (Salk et al., 2017). The finding of lower female self-perceptions is typically generated in variable centered studies which compare the mean values of female and male perceptions. What might have occurred in this study, is identification of two sub-groups of students, more likely to be female and with more negative perceptions, that were split by the profile analysis away from the highly engaged group with positive perceptions.

Irish ethnicity also predicted profile membership, with fewer Irish students identifying as Irish in the attentive disaffected and disengaged profiles. In other words, there were more students from external world regions in the profiles with less positive forms of momentary task engagement. There are several potential explanations for this finding. First, students who are ethnic minorities in classrooms have been documented to have lower levels of school belonging and engagement, due to their experience of ethnic incongruence (Benner \& Graham, 2007), and in this study, this lack of connection might have manifest in their more negative forms of momentary task engagement, via their lower cognitive and emotional engagement. A second possibility is that these students found it more difficult to access the English grammar task, due to language barriers (Rodríguez-Izquierdo \& Darmody, 2019) and this might have also impacted their engagement by engendering feelings of frustration and disinterest. In future research we 
will aim to measure the number of years students have spent living in Ireland, to complement the world regions data.

\section{Discussion of Research Question 3 Findings}

Next, we tested the impact of subjective and objective facilitators of momentary task engagement, on the profile membership. Educational goals were high across the profiles, which fits with recent development research on the growth of motivation in adolescence and young adulthood, which found that adolescents had high utility value for studying across schooling (Symonds et al., 2019). Family support also did not predict profile membership.

However, other subjective facilitators had a notable impact. Having lower academic selfefficacy increased the likelihood of students being in the less engaged profiles, and this impact was strongest for the likelihood of students being in the disengaged profile. This finding is in line with Xie et al. (2019) who used ESM to demonstrate a positive association between program and task self-efficacy and different elements of student engagement. Following expectancy-value theory (e.g. Rosenzweig et al., 2019), possibly in the current study, having lower academic-self efficacy might have encouraged students to form a negative expectation that they would not do well on, or be able to complete the task. It is possible that these students felt themselves unsuccessful when doing similar English grammar tasks in the past. This might have encouraged them to feel disillusioned in the moment, promoting fewer feelings of interest and enjoyment, and less willingness to try hard.

Having lower peer support also predicted being in the attentive disinterested and attentive disaffected profiles. There, students who had more negative experiences of cognitive and emotional engagement, also reported being less well supported at school by their friends. This result fits in part with Cappella et al., (2013) who found that the equality of students' social 
networks within classrooms helped promote students' engagement, and with Nelson and DeBacker (2008) who found that achievement motivation is lower for students who perceive less supportive friendships at school.

Furthermore, in our study the two internally concurrent engagement profiles (engaged and disengaged) were similar in levels of peer support. This might suggest that two different types of supportive peer cultures existed for students in those profiles: one a peer culture of conformity and academic achievement, and the other a peer culture of non-conformity and academic non-compliance. These types of 'conformist' and 'deviant' peer groups are observed to form in the first few years of secondary schooling (Palacios et al., 2019), and are used by students to gain social status in the new peer group (e.g., Symonds, 2015). Fitting with these observations, behavioral engagement, and not cognitive nor emotional engagement, is found to drive homophily, where students with higher or lower levels of behavioral engagement seek out and form friendship networks with students similar in levels of behavioral engagement to themselves (Wang et al., 2018). This can create networks of social support for both highly emotionally/cognitively engaged students and students who are disaffected.

Finally, from the objective facilitators tested, only students' classmates' cognitive engagement predicted profile membership. Specifically, students who were highly behaviorally engaged were also more likely to be in profiles where they were also less cognitively and emotionally engaged, if their classmates were less cognitively engaged in the task. This finding could reflect homophily in the classroom setting, where students in the same classrooms had similar levels of cognitive engagement in classwork, owing to the tendency for groups of students to become more similar on measures of cognitive engagement across time (Wang et al., 2018). This could have occurred in combination with students' ability to act behaviorally 
engaged for the purpose of pleasing the teacher or researcher - even though they were psychologically disaffected with the task (Miserandino, 1996).

\section{Limitations and Suggestions for Future Research}

The current study was limited in several ways, that can primarily be addressed by further research on the same topic. First, there was no in-depth investigation into how the students felt about the task, after the task was completed. Therefore, we have no qualitative data to help explain our findings. We suggest that future research interview a sub-sample of students about their experiences of a task and connect this to any quantitative differences in task engagement that are observed.

Second, there were limitations regarding our measures. Our measure of behavioral engagement combined observations of students being on-task alone and on-task with a friend. Future research may wish to separate these categories to generate more knowledge on specific forms of behavioral engagement in classrooms. Furthermore, our measures of momentary cognition and motivation were student self-report. Other types of measures to combat overreliance on self-report would have strengthened the study, for example emotion recognition software that could have yielded qualitative data on students' emotions while doing the task (Bahreini et al., 2016), and analysis of students' task completion and accuracy as a further indicator of their cognitive and behavioral momentary engagement.

Finally, although using the one type of task enabled us to limit the effects of task differences on the engagement responses, using a set of tasks with different qualities to each other, in a larger sample of students, would allow researchers to identify how forms of engagement might differ in response to different tasks, yielding valuable information for educators. 


\section{Conclusion}

The main finding of this study is that across two schools and 16 classes, seven main types of momentary engagement (and disengagement) emerged in response to the same literacy task, and that these forms of momentary engagement were relatively evenly distributed within classrooms. Like the metaphor of a silver lining inside a grey cloud, students were engaged on some indicators but not on others. Also, like white clouds and or storm clouds, other students were engaged, or disengaged, on all indicators. Building on previous work by Schmidt et al. (2018), this draws attention to the diversity in students' engagement responses even when they are faced with the same task, classmates, and physical context for learning.

These different forms of engagement were associated with gender, Irish ethnicity, selfefficacy, peer support, and classmate cognition. Although we tested whether different types of predictors (individual characteristics, subjective facilitators of engagement, and objective facilitators of engagement) were more impactful than others, we found that a combination of predictor types - individual, subjective and objective - increased the chances for students to have particular forms of engagement. Together, these findings signal that student engagement interventions should target multiple levers of change, including helping students support each other socially and academically to protect against cognitive and emotional disengagement, promoting ethnic inclusion in classrooms to engage students of minority ethnicities, and developing students' academic self-efficacy to enable their educational resilience in moments where they need to stay engaged despite the odds. 


\section{References}

Appleton, J. J., Christenson, S. L., Kim, D., \& Reschly, A. L. (2006). Measuring cognitive and psychological engagement: Validation of the Student Engagement Instrument. Journal of School Psychology, 44(5), 427-445. https://doi.org/10.1016/j.jsp.2006.04.002

Archambault, I., \& Dupéré, V. (2017). Joint trajectories of behavioral, affective, and cognitive engagement in elementary school. The Journal of Educational Research, 110(2), 188198. https://doi.org/10.1080/00220671.2015.1060931

Bahreini, K., Nadolski, R., \& Westera, W. (2016). Towards real-time speech emotion recognition for affective e-learning. Education and Information Technologies, 21(5), 1367-1386. https://doi.org/10.1007/s10639-015-9388-2

Blatchford, P., Bassett, P., \& Brown, P. (2011). Examining the effect of class size on classroom engagement and teacher-pupil interaction: Differences in relation to pupil prior attainment and primary vs. secondary schools. Learning and Instruction, 21(6), 715-730. https://doi.org/10.1016/j.learninstruc.2011.04.001

Cappella, E., Kim, H. Y., Neal, J. W., \& Jackson, D. R. (2013). Classroom peer relationships and behavioral engagement in elementary school: The role of social network equity. American Journal Of Community Psychology, 52(3), 367-379. https://doi.org/10.1007/s10464-013-9603-5

Christenson, S. L., Reschly, A. L., \& Wylie, C. (Eds.). (2012). Handbook of research on student engagement. Springer.

Csikszentmihalyi, M. (2008). Flow: the psychology of optimal experience. Harper Perennial.

Dietrich, J., Moeller, J., Guo, J., Viljaranta, J., \& Kracke, B. (2019). In-the-Moment Profiles of Expectancies, Task Values, and Costs. Frontiers in Psychology, 10(1662). https://doi.org/10.3389/fpsyg.2019.01662 
Fredricks, J., Blumenfeld, P., \& Paris, A. (2004). School engagement: potential of the concept, state of the evidence. Review of Educational Research, 74(1), 59-109. https://www.jstor.org/stable/3516061

Fredricks, J. A., Wang, M.-T., Schall Linn, J., Hofkens, T. L., Sung, H., Parr, A., \& Allerton, J. (2016). Using qualitative methods to develop a survey measure of math and science engagement. Learning and Instruction, 43, 5-15. https://doi.org/10.1016/j.learninstruc.2016.01.009

Hargreaves, L., \& Galton, M. (Eds.). (2002). Transfer from the primary classroom 20 years on. RoutledgeFalmer.

Howard-Jones, P., Ioannou, K., Bailey, R., Prior, J., Hui Yau, S., \& Jay, T. (2018). Applying the science of learning in the classroom. Impact: Journal of the Chartered College of Teaching (Issue 2: Science of Learning). https://impact.chartered.college/article/howardjones-applying-science-learning-classroom/

Hsieh, Y.-H., Lin, Y.-C., \& Hou, H.-T. (2016). Exploring the role of flow experience, learning performance and potential behavior clusters in elementary students' game-based learning. Interactive Learning Environments, 24(1), 178-193. https://doi.org/10.1080/10494820.2013.834827

Kelley, J., Evans, M. D. R., Lowman, J., \& Lykes, V. (2017). Group-mean-centering independent variables in multi-level models is dangerous. Quality \& Quantity, 51(1), 261-283. https://doi.org/10.1007/s11135-015-0304-z

Kuo, M., Browning, M. H. E. M., \& Penner, M. L. (2018). Do lessons in nature boost subsequent classroom engagement? refueling students in flight. Frontiers in Psychology, 8(2253). https://doi.org/10.3389/fpsyg.2017.02253 
Lau, S., \& Roeser, R. W. (2002). Cognitive abilities and motivational processes in high school students' situational engagement and achievement in science. Educational Assessment, 8(2), 139-162. https://doi.org/10.1207/S15326977EA0802_04

Maynard, B. R., Salas-Wright, C. P., Vaughn, M. G., \& Peters, K. E. (2012). Who are truant youth? Examining distinctive profiles of truant youth using latent profile analysis. Journal of Youth and Adolescence, 41(12), 1671-1684. https://doi.org/10.1007/s10964$\underline{012-9788-1}$

Measor, L., \& Woods, P. (1984). Changing schools. Open University Press.

Miserandino, M. (1996). Children who do well in school: Individual differences in perceived competence and autonomy in above-average children. Journal of Educational Psychology, 88(2), 203-214. https://doi.org/10.1037/0022-0663.88.2.203

Mistry, R. S., Benner, A. D., Tan, C. S., \& Kim, S. Y. (2009). Family economic stress and academic well-being among Chinese-American youth: The influence of adolescents' perceptions of economic strain. Journal of Family Psychology, 23(3), 279-290. https://doi.org/10.1037/a0015403

Nelson, R. M., \& DeBacker, T. K. (2008). Achievement motivation in adolescents: The role of peer climate and best friends. The Journal of Experimental Education, 76(2), 170-189. https://doi.org/10.3200/JEXE.76.2.170-190

Ng, S. K., Xiang, L., \& Yau, K. K. W. (2019). Mixture modelling for medical and health sciences: CRC Press, Taylor \& Francis Group.

Nylund, K. L., Asparouhov, T., \& Muthén, B. O. (2007). Deciding on the number of classes in latent class analysis and growth mixture modeling: A monte carlo simulation study. 
Structural Equation Modeling: A Multidisciplinary Journal, 14(4), 535-569. https://doi.org/10.1080/10705510701575396

Oberski, D. (2016). Mixture models: latent profile and latent class analysis. In R. J. \& K. M. (Eds.), Statistical Methods for HCI. Human-Computer Interaction Series. Cham: Springer. https://doi.org/10.1007/978-3-319-26633-6_12

Palacios, D., Dijkstra, J. K., Villalobos, C., Treviño, E., Berger, C., Huisman, M., \& Veenstra, R. (2019). Classroom ability composition and the role of academic performance and school misconduct in the formation of academic and friendship networks. Journal of School Psychology, 74, 58-73. https://doi.org/10.1016/j.jsp.2019.05.006

Patall, E. A., Vasquez, A. C., Steingut, R. R., Trimble, S. S., \& Pituch, K. A. (2016). Daily interest, engagement, and autonomy support in the high school science classroom. Contemporary Educational Psychology, 46, 180-194. https://doi.org/10.1016/j.cedpsych.2016.06.002

Pintrich, P. R., Smith, D. A. F., Garcia, T., \& Mckeachie, W. J. (1993). Reliability and predictive validity of the motivated strategies for learning questionnaire (Mslq). Educational and Psychological Measurement, 53(3), 801-813. https://doi.org/10.1177/0013164493053003024

Pollard, A. (1985). The social world of the primary school (UK Ed.). Cassell.

Rimm-Kaufman, S. E., Baroody, A. E., Larsen, R. A. A., Curby, T. W., \& Abry, T. (2015). To what extent do teacher-student interaction quality and student gender contribute to fifth graders' engagement in mathematics learning? Journal of Educational Psychology, 107(1), 170-185. https://doi.org/10.1037/a0037252 
Rodríguez-Izquierdo, R. M., \& Darmody, M. (2019). Policy and practice in language support for newly arrived migrant children in Ireland and Spain. British Journal of Educational Studies, 67(1), 41-57. https://doi.org/10.1080/00071005.2017.1417973

Rosenzweig, E. Q., Wigfield, A., \& Eccles, J. S. (2019). Expectancy-value theory and Its relevance for student motivation and learning. In K. A. Renninger \& S. E. Hidi (Eds.), The Cambridge Handbook of Motivation and Learning (pp. 617-644). Cambridge University Press.

Salk, R. H., Hyde, J. S., \& Abramson, L. Y. (2017). Gender differences in depression in representative national samples: Meta-analyses of diagnoses and symptoms. Psychological Bulletin, 143(8), 783-822. https://doi.org/10.1037/bul0000102

Salmela-Aro, K., Kiuru, N., Leskinen, E., \& Nurmi, J.-E. (2009). School burnout inventory (SBI): Reliability and validity. European Journal of Psychological Assessment, 25(1), 48-57. https://doi.org/10.1027/1015-5759.25.1.48

Salmela-Aro, K., Moeller, J., Schneider, B., Spicer, J., \& Lavonen, J. (2016 a). Integrating the light and dark sides of student engagement using person-oriented and situation-specific approaches. Learning and Instruction, 43, 61-70. https://doi.org/10.1016/j.learninstruc.2016.01.001

Salmela-Aro, K., Muotka, J., Alho, K., Hakkarainen, K., \& Lonka, K. (2016 b). School burnout and engagement profiles among digital natives in Finland: a person-oriented approach. European Journal of Developmental Psychology, 13(6), 704-718. https://doi.org/10.1080/17405629.2015.1107542 
Salmela-Aro, K., \& Upadyaya, K. (2012). The Schoolwork Engagement Inventory: Energy, dedication, and absorption (EDA). European Journal of Psychological Assessment, 28(1), 60-67. https://doi.org/10.1027/1015-5759/a000091

Schmidt, J. A., Rosenberg, J. M., \& Beymer, P. N. (2018). A person-in-context approach to student engagement in science: Examining learning activities and choice. Journal of Research in Science Teaching, 55(1), 19-43. https://doi.org/10.1002/tea.21409

Schneider, B., Krajcik, J., Lavonen, J., Salmela-Aro, K., Broda, M., Spicer, J., Bruner, J., Moeller, J., Linnansaari, J., Juuti, K. \& Viljaranta, J. (2016). Investigating optimal learning moments in U.S. and Finnish science classes. Journal of Research in Science Teaching, 53(3), 400-421. https://doi.org/10.1002/tea.21306

Schreiber, J. B. (2017). Latent class analysis: An example for reporting results. Research in Social and Administrative Pharmacy, 13(6), 1196-1201. https://doi.org/10.1016/j.sapharm.2016.11.011

Shernoff, D. J., Kelly, S., Tonks, S. M., Anderson, B., Cavanagh, R. F., Sinha, S., \& Abdi, B. (2016). Student engagement as a function of environmental complexity in high school classrooms. Learning and Instruction. https://doi.org/10.1016/j.learninstruc.2015.12.003

Sinatra, G. M., Heddy, B. C., \& Lombardi, D. (2015). The challenges of defining and measuring student engagement in science. Educational Psychologist, 50(1), 1-13. https://doi.org/10.1080/00461520.2014.1002924

Skinner, E. A., \& Pitzer, J. R. (2012). Developmental dynamics of student engagement, coping and everyday resilience. In S. L. Christenson, A. L. Reschly, \& C. Wylie (Eds.), Handbook of research on school engagement (pp. 21-44). Springer. 
Skinner, E. (2016). Engagement and disaffection as central to processes of motivational resilience and development. In K. R. Wentzel \& D. B. Miele (Eds.), Handbook of Motivation at School (pp. 145-168). Routledge.

Symonds, J. E., \& Galton, M. (2014). Moving to the next school at age 10-14 years: an international review of psychological development at school transition. Review of Education, 2(1), 1-27. https://doi.org/10.1002/rev3.3021

Symonds, J. (2015). Understanding school transition: what happens to children and how to help them. Routledge.

Symonds, J., Schoon, I., \& Salmela-Aro, K. (2016). Developmental trajectories of emotional disengagement from schoolwork and their longitudinal associations in England. British Educational Research Journal, 42(6), 993-1022. https://doi.org/10.1002/berj.3243

Symonds, J., Schoon, I., Eccles, J., \& Salmela-Aro, K. (2019). The Development of Motivation and Amotivation to Study and Work across Age-Graded Transitions in Adolescence and Young Adulthood. Journal of Youth and Adolescence, 48(6), 1131-1145. https://doi.org/10.1007/s10964-019-01003-4

Symonds, J. E., Kaplan, A., Upadyaya, K., Salmela-Aro, K., Torsney, B., Skinner, E., \& Eccles, J. (2019). Momentary student engagement as a dynamic developmental system. https://psyarxiv.com/fuy7p/

Taleb, N. N. (2018). Skin in the game: Hidden asymmetries in daily life. Random House.

Tuominen-Soini, H., \& Salmela-Aro, K. (2014). Schoolwork engagement and burnout among Finnish high school students and young adults: Profiles, progressions, and educational outcomes. Developmental Psychology, 50(3), 649-662. https://doi.org/10.1037/a0033898 
van Rooij, E. C. M., Jansen, E. P. W. A., \& van de Grift, W. J. C. M. (2017). Secondary school students' engagement profiles and their relationship with academic adjustment and achievement in university. Learning and Individual Differences, 54, 9-19. https://doi.org/10.1016/j.lindif.2017.01.004

Virtanen, T. E., Lerkkanen, M. K., Poikkeus, A. M., \& Kuorelahti, M. (2018). Student engagement and school burnout in Finnish lower-secondary schools: Latent profile analysis. Scandinavian Journal of Educational Research, 62(4), 519-537. https://doi.org/10.1080/00313831.2016.1258669

Wang, M.-T., \& Eccles, J. S. (2012 a). Social support matters: Longitudinal effects of social support on three dimensions of school engagement from middle to high school. Child Development, 83(3), 877-895. https://doi.org/10.1111/j.1467-8624.2012.01745.x

Wang, M.-T., \& Eccles, J. S. (2012 b). Adolescent behavioral, emotional, and cognitive engagement trajectories in school and their differential relations to educational success. Journal of Research on Adolescence, 22(1), 31-39. https://doi.org/10.1111/j.15327795.2011.00753.x

Wang, M.-T., Fredricks, J., Ye, F., Hofkens, T. L., \& Linn, J. S. (2016). The Math and Science Engagement Scales: Scale development, validation, and psychometric properties. Learning and Instruction, 43, 16-26. https://doi.org/10.1027/1015-5759/a000431

Wang, M.-T., Kiuru, N., Degol, J. L., \& Salmela-Aro, K. (2018). Friends, academic achievement, and school engagement during adolescence: A social network approach to peer influence and selection effects. Learning and Instruction, 58, 148-160. https://doi.org/10.1016/j.learninstruc.2018.06.003 
Wang, M.-T., \& Peck, S. C. (2013). Adolescent educational success and mental health vary across school engagement profiles. Developmental Psychology, 49(7), 1266-1276. https://doi.org/10.1037/a0030028

Watt, H. M. G., Carmichael, C., \& Callingham, R. (2017). Students' engagement profiles in mathematics according to learning environment dimensions: Developing an evidence base for best practice in mathematics education. School Psychology International, 38(2), 166-183. https://doi.org/10.1177/0143034316688373

Wasserstein, R. L., Schirm, A. L., \& Lazar, N. A. (2019). Moving to a world beyond "p < 0.05". The American Statistician, 73(sup1), 1-19. https://doi.org/10.1080/00031305.2019.1583913

Watt, H. M. G., Bucich, M., \& Dacosta, L. (2019). Adolescents' motivational profiles in mathematics and science: associations with achievement striving, career aspirations and psychological wellbeing. Frontiers in Psychology, 10, 990-990. https://doi.org/10.3389/fpsyg.2019.00990

Widlund, A., Tuominen, H., \& Korhonen, J. (2018). Academic well-being, mathematics performance, and educational aspirations in lower secondary education: Changes within a school year. Frontiers in Psychology, 9(297). https://doi.org/10.3389/fpsyg.2018.00297

Xie, K., Heddy, B. C., \& Vongkulluksn, V. W. (2019). Examining engagement in context using experience-sampling method with mobile technology. Contemporary Educational Psychology, 59, 101788. https://doi.org/10.1016/j.cedpsych.2019.101788 


\section{Tables and Figures}

Table 1.

Person-Oriented Analysis of School and Task Engagement

\begin{tabular}{|c|c|c|c|c|}
\hline & Authors & Title & Location & $\begin{array}{l}\text { Grain } \\
\text { Size }\end{array}$ \\
\hline 1 & $\begin{array}{l}\text { Schmidt, Rosenberg } \\
\text { \& Beymer (2018) }\end{array}$ & $\begin{array}{l}\text { A Person-in-Context Approach to Student } \\
\text { Engagement in Science: Examining Learning } \\
\text { Activities and Choice }\end{array}$ & USA & Task \\
\hline 2 & $\begin{array}{l}\text { Hsieh, Lin \& Hou } \\
\text { (2016) }\end{array}$ & $\begin{array}{l}\text { Exploring the Role of Flow Experience, Learning } \\
\text { Performance and Potential Behavior Clusters in } \\
\text { Elementary Students' Game-Based Learning }\end{array}$ & Taiwan & Task \\
\hline 3 & Li \& Lerner (2011) & $\begin{array}{l}\text { Trajectories of School Engagement during } \\
\text { Adolescence: Implications for Grades, } \\
\text { Depression, Delinquency, and Substance Use }\end{array}$ & USA & School \\
\hline 4 & $\begin{array}{l}\text { Maynard, Salas- } \\
\text { Wright, Vaughn \& } \\
\text { Peters (2012) }\end{array}$ & $\begin{array}{l}\text { Who are truant youth? Examining distinctive } \\
\text { profiles of truant youth using latent profile } \\
\text { analysis }\end{array}$ & USA & School \\
\hline 5 & $\begin{array}{l}\text { Salmela-Aro, } \\
\text { Muotka, Alho, } \\
\text { Hakkarainen \& } \\
\text { Lonka (2016) }\end{array}$ & $\begin{array}{l}\text { School burnout and engagement profiles among } \\
\text { digital natives in Finland: A person-oriented } \\
\text { approach }\end{array}$ & Finland & School \\
\hline 6 & $\begin{array}{l}\text { Salmela-Aro, } \\
\text { Moeller, Schneider, } \\
\text { Spicer, \& Lavonen } \\
(2016)\end{array}$ & $\begin{array}{l}\text { Integrating the light and dark sides of student } \\
\text { engagement using person-oriented and situation- } \\
\text { specific approaches }\end{array}$ & Finland & School \\
\hline 7 & $\begin{array}{l}\text { Tuominen-Soini \& } \\
\text { Salmela-Aro (2014) }\end{array}$ & $\begin{array}{l}\text { Schoolwork Engagement and Burnout among } \\
\text { Finnish High School Students and Young Adults: } \\
\text { Profiles, Progressions, and Educational Outcomes }\end{array}$ & Finland & School \\
\hline 8 & $\begin{array}{l}\text { van Rooij, Jansen \& } \\
\text { van de Grift (2017) }\end{array}$ & $\begin{array}{l}\text { Secondary school students' engagement profiles } \\
\text { and their relationship with academic adjustment } \\
\text { and achievement in university }\end{array}$ & Netherlands & School \\
\hline 9 & $\begin{array}{l}\text { Virtanen, } \\
\text { Lerkkanen, } \\
\text { Poikkeus \& } \\
\text { Kuorelahti (2018) }\end{array}$ & $\begin{array}{l}\text { Student Engagement and School Burnout in } \\
\text { Finnish Lower-Secondary Schools: Latent Profile } \\
\text { Analysis }\end{array}$ & Finland & School \\
\hline 10 & $\begin{array}{l}\text { Wang \& Peck } \\
(2013)\end{array}$ & $\begin{array}{l}\text { Adolescent Educational Success and Mental } \\
\text { Health Vary across School Engagement Profiles }\end{array}$ & USA & School \\
\hline 11 & $\begin{array}{l}\text { Watt, Carmichael \& } \\
\text { Callingham (2017) }\end{array}$ & $\begin{array}{l}\text { Students' engagement profiles in mathematics } \\
\text { according to learning environment dimensions: } \\
\text { Developing an evidence base for best practice in } \\
\text { mathematics education }\end{array}$ & Australia & School \\
\hline 12 & $\begin{array}{l}\text { Widlund, Tuominen } \\
\text { \& Korhonen (2018) }\end{array}$ & $\begin{array}{l}\text { Academic well-being, mathematics performance, } \\
\text { and educational aspirations in lower secondary } \\
\text { education: Changes within a school year }\end{array}$ & Finland & School \\
\hline
\end{tabular}


Table 2.

Descriptive Statistics

\begin{tabular}{lrrrrrr}
\hline & N & Range & Min & Max & M & SD \\
\hline Individual characteristics & & & & & & \\
Age in months & 186 & 37 & 144 & 181 & 158.90 & 8.46 \\
Male vs. female & 194 & 1 & 1 & 2 & 1.49 & .50 \\
Irish vs other ethnicity & 188 & 1 & 0 & 1 & 0.72 & .45 \\
Economic advantage & 167 & 4 & 1 & 5 & 4.04 & .98 \\
Momentary engagement & & & & & & \\
Behavioral engagement & 187 & 5 & 0 & 5 & 3.95 & 1.32 \\
Emotional engagement & 195 & 4 & 1 & 5 & 3.24 & .97 \\
Cognitive engagement & 195 & 4 & 1 & 5 & 2.63 & 1.06 \\
Perceived facilitators & & & & & & \\
Self-efficacy & 173 & 4 & 2 & 6 & 4.76 & .76 \\
Educational goals & 177 & 5 & 1 & 6 & 5.24 & 1.00 \\
Teacher support & 177 & 5 & 1 & 6 & 4.61 & 1.02 \\
Peer support & 177 & 4 & 2 & 6 & 4.71 & .89 \\
Family support & 176 & 5 & 1 & 6 & 5.36 & .73 \\
Objective facilitators & & & & & & \\
Classmate behavior & 188 & 8 & 1 & 9 & 5.45 & 2.52 \\
Classmate emotion & 195 & 2 & 2 & 3 & 2.65 & .34 \\
Classmate cognition & 195 & 2 & 2 & 4 & 3.19 & .37 \\
\hline
\end{tabular}




\section{Table 3.}

Correlations Between Study Variables

\begin{tabular}{|c|c|c|c|c|c|c|c|c|c|c|c|c|c|c|c|}
\hline & & 1 & 2 & 3 & 4 & 5 & 6 & 7 & 8 & 9 & 10 & 11 & 12 & 13 & 14 \\
\hline 1 & Age in months & 1.00 & & & & & & & & & & & & & \\
\hline 2 & Male vs. female & -.02 & 1.00 & & & & & & & & & & & & \\
\hline 3 & Irish vs. other ethnicity & $-.18 *$ & -.01 & 1.00 & & & & & & & & & & & \\
\hline 4 & Economic advantage & .03 & .02 & -.06 & 1.00 & & & & & & & & & & \\
\hline 5 & Behavioral engagement & -.02 & -.06 & -.03 & -.03 & 1.00 & & & & & & & & & \\
\hline 6 & Emotional engagement & -.07 & .08 & $.20 * *$ & -.02 & $.21 * *$ & 1.00 & & & & & & & & \\
\hline 7 & Cognitive engagement & -.10 & .10 & .13 & .02 & $.21 * *$ & $.44 * * *$ & 1.00 & & & & & & & \\
\hline 8 & Self-efficacy & -.03 & -.08 & -.04 & .13 & $.17 *$ & $.16^{*}$ & $.22 * *$ & 1.00 & & & & & & \\
\hline 9 & Educational goals & -.06 & -.13 & -.02 & $.17^{*}$ & .07 & .13 & $.21 * *$ & $.50 * * *$ & 1.00 & & & & & \\
\hline 10 & Teacher support & -.09 & -.05 & $.22 * *$ & -.01 & .15 & $.20 * *$ & $.16^{*}$ & $.43 * * *$ & $.36 * * *$ & 1.00 & & & & \\
\hline 11 & Peer support & -.02 & -.02 & $.24 * *$ & .11 & -.15 & .01 & .05 & $.23 * *$ & .13 & $.24 * * *$ & 1.00 & & & \\
\hline 12 & Family support & .04 & $-.19 * *$ & $.16^{*}$ & .11 & .04 & .03 & $.20 * *$ & $.42 * * *$ & $.28 * * *$ & $.28 * * *$ & $.42 * * *$ & 1.00 & & \\
\hline 13 & Classmate behavior & .01 & .05 & -.10 & -.05 & $.29 * * *$ & .01 & -.13 & -.04 & -.08 & -.07 & -.03 & .03 & 1.00 & \\
\hline 14 & Classmate emotion & $-.16^{*}$ & .07 & .13 & -.01 & -.08 & $.18^{* *}$ & .14 & -.04 & -.01 & $.16^{*}$ & .05 & .02 & $-.28 * * *$ & 1.00 \\
\hline 15 & Classmate cognition & -.14 & .06 & .13 & -.09 & -.03 & $.24 * * *$ & $.19 * *$ & -.01 & -.09 & $.16^{*}$ & .07 & .08 & .05 & $.75 * * *$ \\
\hline
\end{tabular}

Note. $* * * p<.05, * * p<.01, * p<.001$. 
Table 4.

Latent Profile Analysis Model Fit Statistics

\begin{tabular}{|c|c|c|c|c|c|c|c|c|c|c|c|c|c|c|c|c|}
\hline Solution & AIC & adj. BIC & Entropy & BLRT $p$ & $\mathrm{P} 1$ & $\mathrm{P} 2$ & P3 & $\mathrm{P} 4$ & P5 & P6 & P7 & P8 & P9 & P10 & P11 & P12 \\
\hline 1 & 1747 & 1747 & - & - & 196 & & & & & & & & & & & \\
\hline 2 & 1643 & 1644 & .84 & .000 & 154 & 42 & & & & & & & & & & \\
\hline 3 & 1616 & 1617 & .67 & .000 & 71 & 42 & 82 & & & & & & & & & \\
\hline 4 & 1594 & 1596 & .75 & .000 & 76 & 34 & 76 & 10 & & & & & & & & \\
\hline 5 & 1589 & 1592 & .77 & .067 & 59 & 32 & 79 & 14 & & & & & & & & \\
\hline 6 & 1584 & 1587 & .79 & .040 & 55 & 24 & 79 & 15 & 12 & 11 & & & & & & \\
\hline 7 & 1576 & 1580 & .78 & .020 & 62 & 26 & 54 & 18 & 12 & 12 & 12 & & & & & \\
\hline 8 & 1571 & 1574 & .80 & .077 & 58 & 23 & 53 & 18 & 14 & 12 & 10 & 8 & & & & \\
\hline 9 & 1565 & 1574 & .82 & .235 & 57 & 21 & 53 & 18 & 14 & 12 & 9 & 8 & 4 & & & \\
\hline 10 & 1561 & 1566 & .84 & .667 & 57 & 21 & 52 & 18 & 14 & 10 & 8 & 7 & 5 & 4 & & \\
\hline 11 & 1560 & 1565 & .84 & 1.000 & 51 & 23 & 44 & 18 & 18 & 11 & 9 & 7 & 6 & 5 & 4 & \\
\hline 12 & 1558 & 1563 & .84 & .077 & 49 & 21 & 37 & 26 & 15 & 13 & 9 & 7 & 6 & 5 & 4 & 4 \\
\hline
\end{tabular}

Notes: adj. BIC $=$ adjusted BIC, VLMR $p=$ Vong-Lo-Mendel-Rubin likelihood ratio test, BLRT $p=$ Bootstrapped likelihood ratio test, $\mathrm{P} 1-\mathrm{P} 12=$ number of cases in profile 1 - profile 12 , seventh solution in bold font to indicate selection.

Table 5 .

Engagement Profiles Descriptive Statistics

\begin{tabular}{|c|c|c|c|c|c|c|c|c|}
\hline & Engaged & & $\begin{array}{l}\text { Attentive } \\
\text { amotivated }\end{array}$ & & $\begin{array}{l}\text { Attentive } \\
\text { disintereste }\end{array}$ & & $\begin{array}{l}\text { Attentive } \\
\text { disaffected }\end{array}$ & \\
\hline $\mathrm{N} \mid \%$ & 54 & 27.6 & 18 & 9.2 & 62 & 31.6 & 12 & 6.1 \\
\hline Behavior $M \mid S D$ & 4.56 & .55 & 4.79 & .33 & 4.65 & .44 & 4.75 & .35 \\
\hline Emotion $M \mid S D$ & 4.11 & .51 & 4.06 & 0.64 & 2.79 & .55 & 2.00 & .85 \\
\hline \begin{tabular}{l|l} 
Cognition $M$ & $S D$ \\
\end{tabular} & 3.68 & .61 & 1.61 & 0.50 & 2.74 & .60 & 1.17 & .39 \\
\hline & $\begin{array}{l}\text { Distracted } \\
\text { motivated }\end{array}$ & & Disengaged & & $\begin{array}{l}\text { Deeply } \\
\text { disengaged }\end{array}$ & & Total & \\
\hline $\mathrm{N} \mid \%$ & 12 & 6.1 & 26 & 13.3 & 12 & 6.1 & 196 & 100 \\
\hline Behavior $M \mid S D$ & 1.96 & .63 & 2.55 & .53 & .83 & .40 & 3.95 & 1.32 \\
\hline Emotion $M \mid S D$ & 3.67 & .78 & 2.77 & .82 & 2.33 & 1.07 & 3.24 & .97 \\
\hline Cognition $M \mid S D$ & 3.58 & .67 & 1.62 & .57 & 1.67 & .78 & 2.63 & 1.06 \\
\hline
\end{tabular}


Table 6.

Multinomial Logistic Regression Results

\begin{tabular}{lrrrrrrrrr}
\hline & \multicolumn{1}{c}{ Attentive disinterested } & \multicolumn{7}{c}{ Attentive disaffected } & \multicolumn{7}{c}{ Disengaged } \\
& $\beta$ & SE & OR & $\beta$ & SE & OR & $\beta$ & SE & OR \\
\hline Individual & & & & & & & & & \\
Age & .10 & .07 & 1.11 & .05 & .03 & 1.05 & .01 & .06 & 1.01 \\
Male vs. female & -2.79 & 1.45 & $.06^{* * *}$ & -.90 & .50 & $.41^{* *}$ & -1.10 & 1.08 & .33 \\
Economic advantage & -.05 & .44 & .95 & -.12 & .30 & .89 & .05 & .28 & 1.05 \\
Irish ethnicity & .21 & .97 & 1.24 & -1.05 & .48 & $.35^{* * *}$ & -1.30 & .79 & $.27 * *$ \\
Subjective & & & & & & & & & \\
Self-efficacy & -.89 & .48 & $.41^{* *}$ & -.54 & .32 & $.58^{*}$ & -1.22 & .46 & $.30^{* * *}$ \\
Educational goals & -.60 & .51 & .55 & -.17 & .24 & .85 & -.39 & .37 & .68 \\
Teacher support & .04 & .40 & 1.04 & -.12 & .36 & .89 & -.64 & .43 & $.53 *$ \\
Peer support & -1.02 & .37 & $.36^{* * *}$ & -.37 & .19 & $.69 *$ & .48 & .34 & 1.61 \\
Family support & .80 & .93 & 2.23 & .15 & .32 & 1.16 & -.11 & .41 & .90 \\
Objective & & & & & & & & & \\
Classmate behavior & .56 & .39 & 1.75 & .06 & .10 & 1.06 & .01 & .25 & 1.01 \\
Classmate emotion & 1.33 & 2.50 & 3.76 & -.59 & .97 & .55 & -.88 & 2.59 & .41 \\
Classmate cognition & -2.96 & 1.78 & $.05^{* * *}$ & -1.51 & 1.19 & $.22 * *$ & -.86 & 2.60 & .43 \\
\hline
\end{tabular}

Note. ${ }^{* * *} p<.05, * * p<.01, * p<.001$. Engaged profile is the reference group 
Table 7 .

Four Main Engagement Profiles Across Classrooms

\begin{tabular}{rrrrrr}
\hline $\begin{array}{l}\text { Classroom } \\
\text { number }\end{array}$ & $\begin{array}{r}\text { Attentive } \\
\text { Disengaged }\end{array}$ & $\begin{array}{c}\text { Attentive } \\
\text { disaffected } \\
\text { amotivated }\end{array}$ & Engaged & Total \\
\hline 1.00 & $7.7 \%$ & $23.1 \%$ & $15.4 \%$ & $53.8 \%$ & $100.0 \%$ \\
2.00 & $12.5 \%$ & $62.5 \%$ & $12.5 \%$ & $12.5 \%$ & $100.0 \%$ \\
3.00 & - & $40.0 \%$ & - & $60.0 \%$ & $100.0 \%$ \\
4.00 & $8.3 \%$ & $66.7 \%$ & $8.3 \%$ & $16.7 \%$ & $100.0 \%$ \\
5.00 & $17.6 \%$ & $17.6 \%$ & $5.9 \%$ & $58.8 \%$ & $100.0 \%$ \\
6.00 & $28.6 \%$ & $57.1 \%$ & - & $14.3 \%$ & $100.0 \%$ \\
7.00 & $20.0 \%$ & $40.0 \%$ & $20.0 \%$ & $20.0 \%$ & $100.0 \%$ \\
8.00 & $16.7 \%$ & $33.3 \%$ & - & $50.0 \%$ & $100.0 \%$ \\
9.00 & $11.8 \%$ & $70.6 \%$ & $11.8 \%$ & $5.9 \%$ & $100.0 \%$ \\
10.00 & $29.4 \%$ & $29.4 \%$ & $17.6 \%$ & $23.5 \%$ & $100.0 \%$ \\
14.00 & $4.8 \%$ & $33.3 \%$ & $23.8 \%$ & $38.1 \%$ & $100.0 \%$ \\
15.00 & $28.6 \%$ & $28.6 \%$ & $14.3 \%$ & $28.6 \%$ & $100.0 \%$ \\
16.00 & $30.8 \%$ & $23.1 \%$ & - & $46.2 \%$ & $100.0 \%$ \\
\hline
\end{tabular}

Note. $* * * p<.05, * * p<.01, * p<.001$. 
Figure 1.

Flow Diagram of Systematic Literature Search

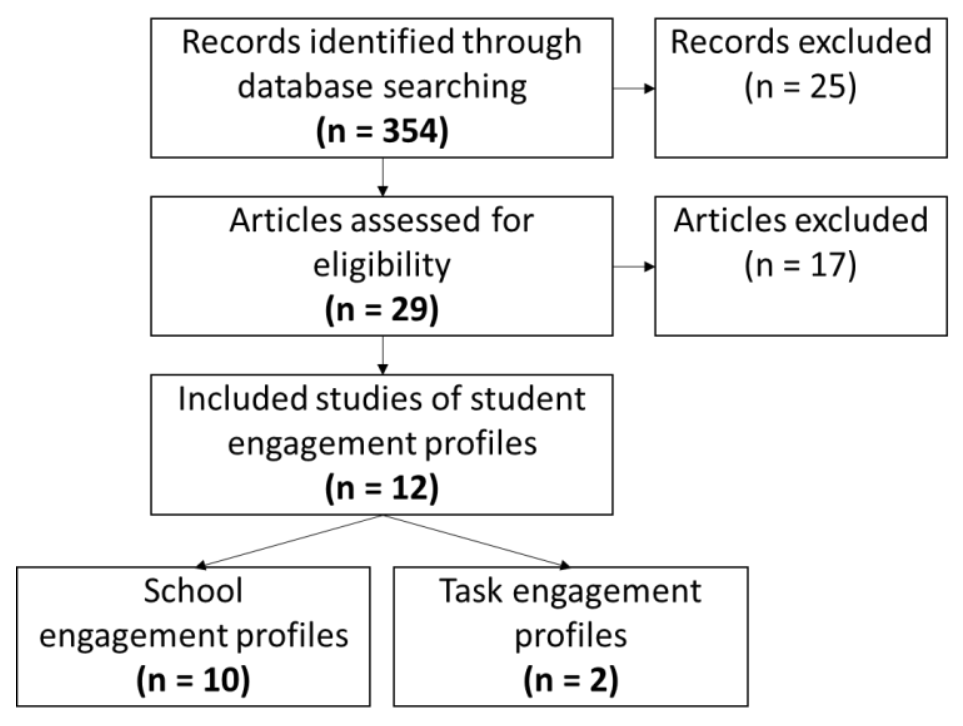

Figure 2.

Momentary Engagement Profiles

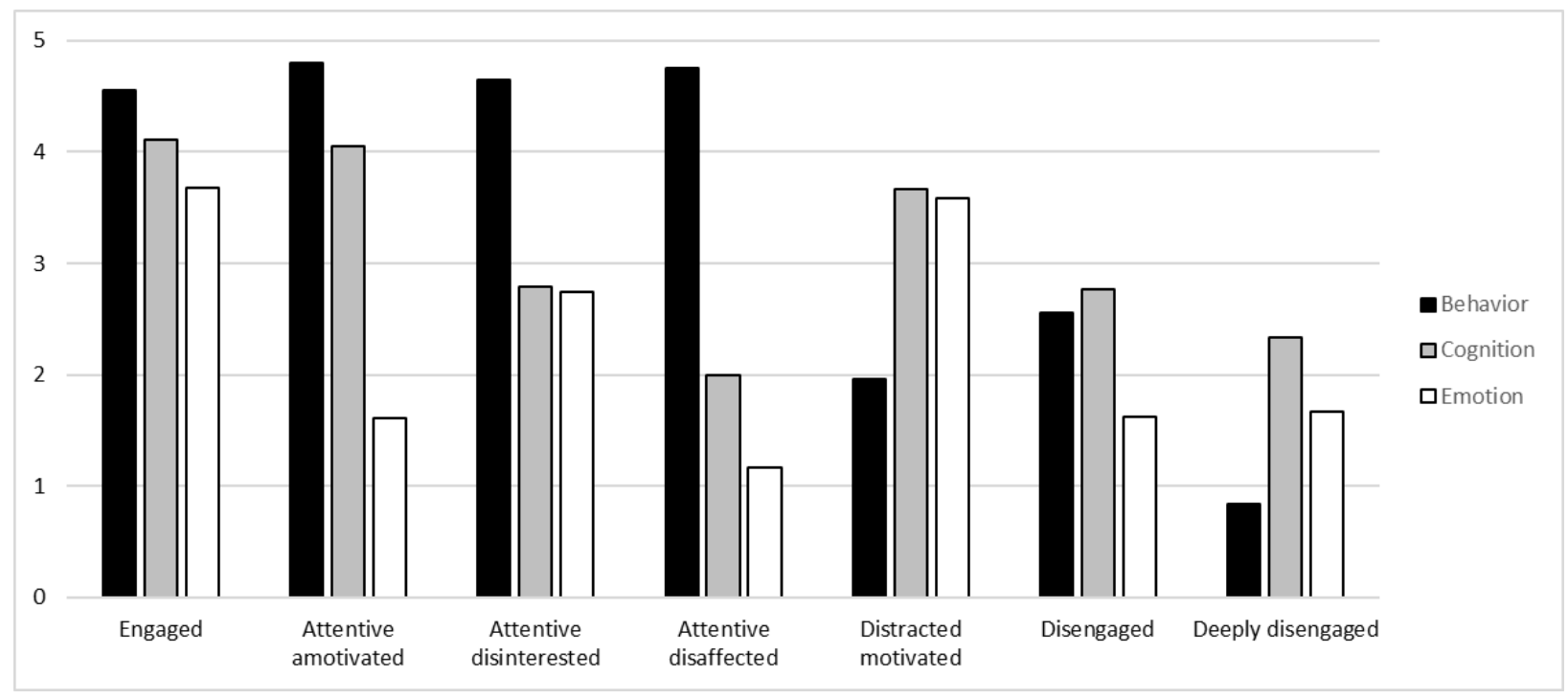

